\title{
Claiming the Place; Informal Placemaking, Power and Territo- rial Identity in Heliopolis, Cairo
}

Sadek Saad

How to cite this paper: Saad, S. (2022). Claiming the Place; Informal Placemaking, Power and Territorial Identity in Heliopolis, Cairo. Journal of Art and Design, 1(1), 46-60. Retrieved from https://www.scipublications.com/journal/index.php/jad/article/view/246

Received: January 1, 2022

Accepted: February 24, 2022

Published: February 25, 2022

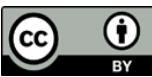

Copyright: (C) 2022 by the authors. Submitted for possible open access publication under the terms and conditions of the Creative Commons Attribution (CC BY) license (http://creativecommons.org/licenses /by/4.0/).

\author{
Architectural and Urban Design, Department of Architectural Engineering, Shobra College of Engineering, \\ Benha University, Cairo, Egypt \\ *Correspondence: sadek.ahmed.saad@gmail.com
}

\begin{abstract}
The bottom-up or informal placemaking process is "illegal", practised only by the "poor" and "unintellectual" classes. The author argues that various classes practise informal placemaking regardless of their economic status or educational level. Studying the spatial manifestation of informal placemaking helps to understand the concrete needs of the residents and reconsider their role in identifying places. Aiming to comprehend informal placemaking and its importance, this study investigates informal placemaking in Sheraton Residence, Heliopolis, Cairo. The area is chosen for its formality, socio-economic and cultural patterns. Cases of informal placemaking in Sheraton Residence are described and analysed to pinpoint their role in creating a sense of place, territorial identity and comprehending their meaning. A comparison with cases in informal low-income housing is conducted to construct diversities and similarities. The study encourages the re-thinking of the public role in placemaking as a place of negotiation and belonging. We can improve their urban quality by re-thinking informal placemaking and looking at how people use the place. The general impression that only informal housing and low-educated classes practise informal placemaking is incorrect.
\end{abstract}

Keywords: Urban Studies; Urban Design; Bottom-up Urbanism; Territoriality; Placemaking; Sense of Place; Place Identity; Cairo

\section{Introduction}

Sims considers Cairo out of control; people might ignore the Egyptian building regulations and exercise informal urbanism [1]. While some classes can pay financial penalties to the state and exercise power, low-income and marginalised classes are forced to live under the authorities' continuous threats. However, when the local authorities neglect their urban duties, various community classes are forced to create their place [2, p. 685]. Placemaking requires the collaboration of the users in creating place identity. Such collaboration is also essential for creating a sense of place and place attachment. In recent years calls have increased to shift the placemaking power from the 'experts-led' decisionmakers to a more collaborative process [3]. Public collaboration in placemaking increases the chances of creating meaningful places, which according to neuroscientific studies, improves mood, support recovery from stress and mental fatigue, support emotional and cognitive self-regulation [4].

\section{Hypnosis, Aim and Methods}

Since urban experiments are essential for urban development, the author argues that studying informal placemaking is vital. Furthermore, informal placemaking is not exercised due to the residents' cultural nevus. It is exercised due to players position in the power network and their need to identify their places. Examining the informal placemak- 
ing significance should help comprehend its role in creating a place of belonging and satisfying individual needs. Several indicators relying heavily on the 'top-down' process are available [5-7]. The author concluded that using place livability indicators might not help understand the true nature of bottom-up placemaking in Heliopolis since using place livability indicators neglects community engagement to the place livability [8, p. 3,4].

This study investigates typical informal placemaking cases in Sheraton Residence, Heliopolis, Cairo. The area is chosen for its residents' economic socio-cultural patterns (accommodating highly-educated and medium- to high-income classes) and its recent construction (the 1970s). The study time frame was chosen in 2019 before the recent events of authoritarian urban interventions and road projects in 2020-2021. By analysing the spatial relation of significant cases, the study analyses how informal placemaking generates places of territorial belonging, negotiation and identity. The study hypnosis can be tested by constructing similarities and diversities, describing and comparing informal placemaking cases in Sheraton Residence and El-Arab areas. El-Arab housing is an informal area (accommodating low-income and low to medium educated classes) accused of illegal urban activities. During the fieldwork, observational walks were combined with spontaneous interviewing for obtaining data. The study develops a central strand of thought: it discusses informal placemaking as a process of producing a place of belonging.

\section{Placemaking; From Space to Place}

While the physical setting and structure define space, the place is related to human activities, socio-cultural and symbolic meanings. The place matters; it allows the spatial unit for exercising belonging and attachment [9]. Furthermore, the space becomes public due to routinised practice and human activities rather than laws of discourse [10]. The Public place encourages a set of concepts, among which 'the right to the city' is unlimited to accessibility and activities [11]. To better comprehend placemaking's values, significant vital dimensions of people-place relationship is to be determined; perception (sensory information), attention (fascination and interest), memory and emotion (attachment and bond) [4]. As space transforms into place according to a whole range of users actions and activities [12], such transformation is created due to users' decisions to facilitate their place belonging and attachment [13].

Various placemaking processes are practised in Cairo, such as the top-down (formal) and bottom-up (informal) processes [14]. The term informal placemaking is used in this study to indicate uncharted, unregistered or "illegal" urban activities practised by individuals or influential parties. Neglecting informal placemaking is unhelpful since individual behavioural choices are essential to promoting environmental sustainability. It should be considered a silent protest and urban reflection of individuals creating a sense of place [15, p. 2387]. On the other hand, top-down, formal or standard placemaking [16] runs the risk of deterioration as funds run out [17], and decision-makers might practise placeless power, which is created due to unconcerned decisions on the community in a particular place [9].

The city is determined by players or physical and non-physical forces such as wealth, authoritarianism or state action, social norms, ideas and the number of players or masses [18]. Players act according to their position in the urban power network's type and level. Power is the ability to make decisions and take actions or make others do what the decision-maker have them do. It is non-physical; thus, it cannot be read, but we can read its physical traces. Power can be traced in urban items reflecting players decisions in a given place [19]. The right to the city should include collaboration, deliberation and place control [20]; thus, bottom-up placemaking should not be overlooked. 


\subsection{Informal Placemaking in Sheraton Residence}

Heliopolis was constructed in 1919, and its physical traditional urban identity is defined by several dimensions such as its significant green areas, street patterns, vast circular round-about and architectural character (Figure 1). It is one of Cairo's formal quarters, known for its residences cultural and socio-economic patterns. After nationalising Heliopolis company -by the middle of the $20^{\text {th }}$ century- it grew exponentially but kept much of its urban identities till the end of the century. Despite gardens importance in encouraging restorativeness [21, p. 1], and they are significant to Heliopolis identity, they were mostly left for decay or became inaccessible (Figure 2). Green-islands are neglected (Figure 3), and pavements become unusable and dirty. Under the economic pressure, medium-income classes suffered; however, they continuously and spontaneously created places as a part of their everyday life [22, p. 136] and practised informal urban activities. In 2020, Heliopolis, among other residential areas in Cairo, witnessed significant topdown urban interventions transforming its street to roads and greenery to asphalt (for more on this subject, read [23]. Despite the increasing evidence of place greenery on health and average age expectancy [24], the authorities eliminated or minimised accessibility to public gardens further.

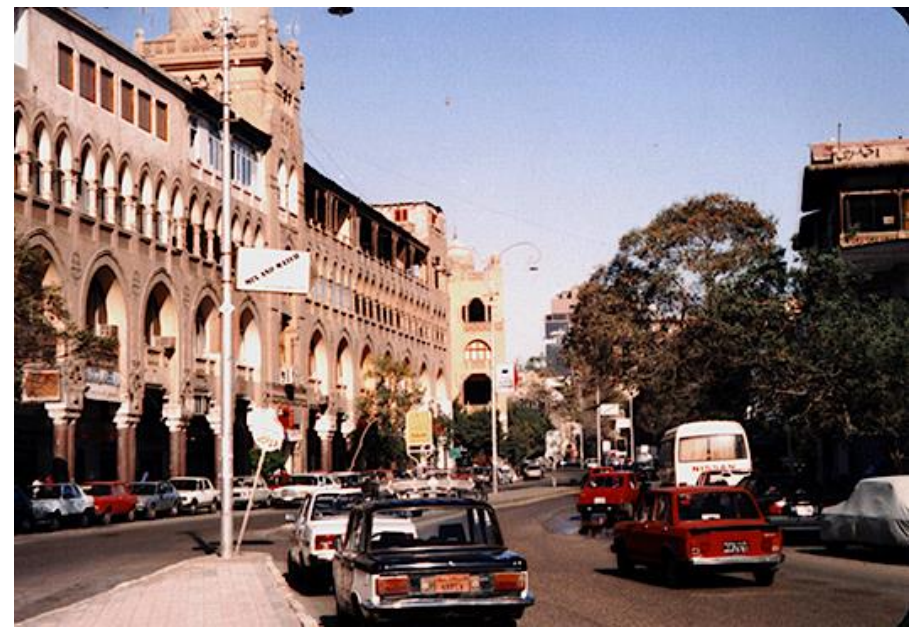

Figure 1. Heliopolis Traditional Character, the author; 1992.

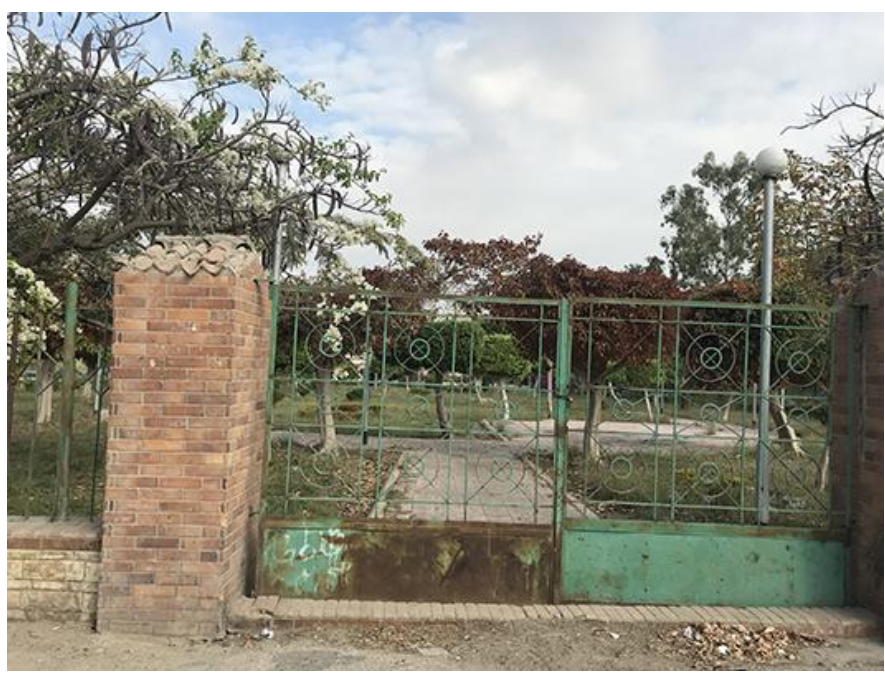

Figure 2. An Inaccessible Public Garden, the author; 2019. 


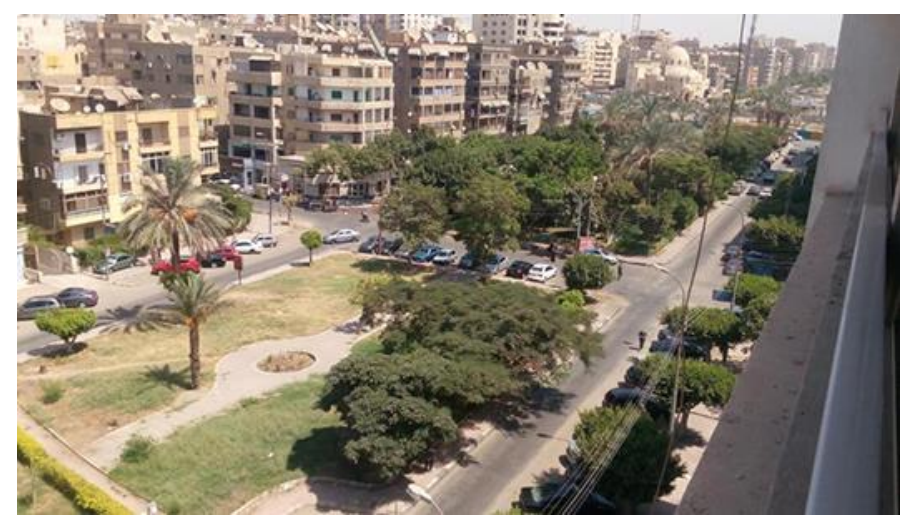

Figure 3. A Neglected Green-Island, the author; 2010.

In eastern Heliopolis, Sheraton Residence flourished by the 1980s as its formal urban extension. Sheraton Residence presents a typical urban case of a newly developed area for medium- to high-income classes. Sayyed Zakaria Street is one of its significant streets developed through a top-down urban process during 1980-1990. A mosque and a communication centre physically divided the street into two sectors. The first sector's green island is well preserved, and the street defining buildings varies between 5-7 floors, mainly constructed by two real estate companies creating clear visual monotony (Figure 4). The residential density is average, and commercial activities were informally created along both sides of the street, generating additional human activities. It was common to observe children playing on the green island, waiting, relaxing, eating and socialising.

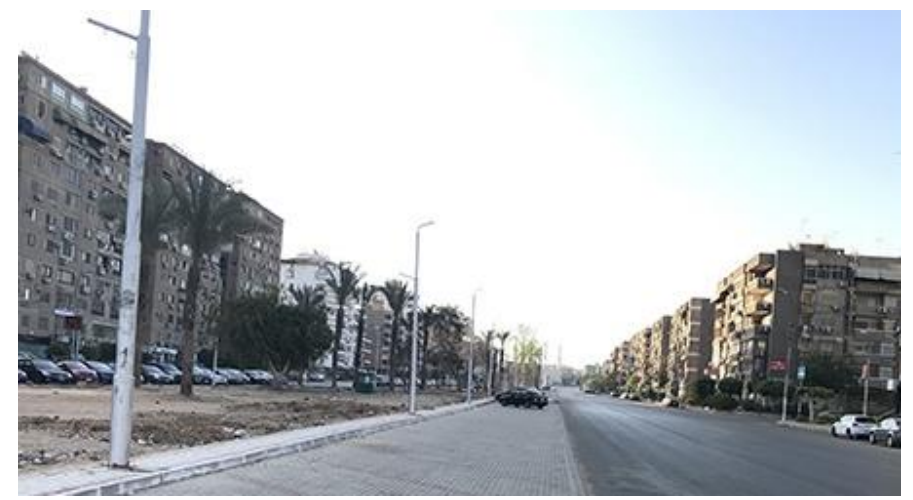

Figure 4. Sayyed Zakaria Street's Architectural Monotony, the author; 2021.

Since the street is devoted to vehicles, informal activities took place on pavements or small parking lots. Trees are used for beautification, social privacy and shading. In several cases, ground floor apartments created private entrances separated from the collective building. The use of shrubs and trees helped hide the private entrance from strangers (Figure 5). Territorial borders in setbacks were developed to express individual control and the self. Informal flower boxes defined the building territory and bollards reserving spots for private parking (Figure 6 and Figure 7). In front of influential institutions such as a police station, a private-sector-company headquarters and a Christian home for elderly persons, territorial borderlines were imposed on the street and pavements 'for security and private use' as interviewees responded (Figure 8, Figure 9, Figure 10 and Figure $11)$. 


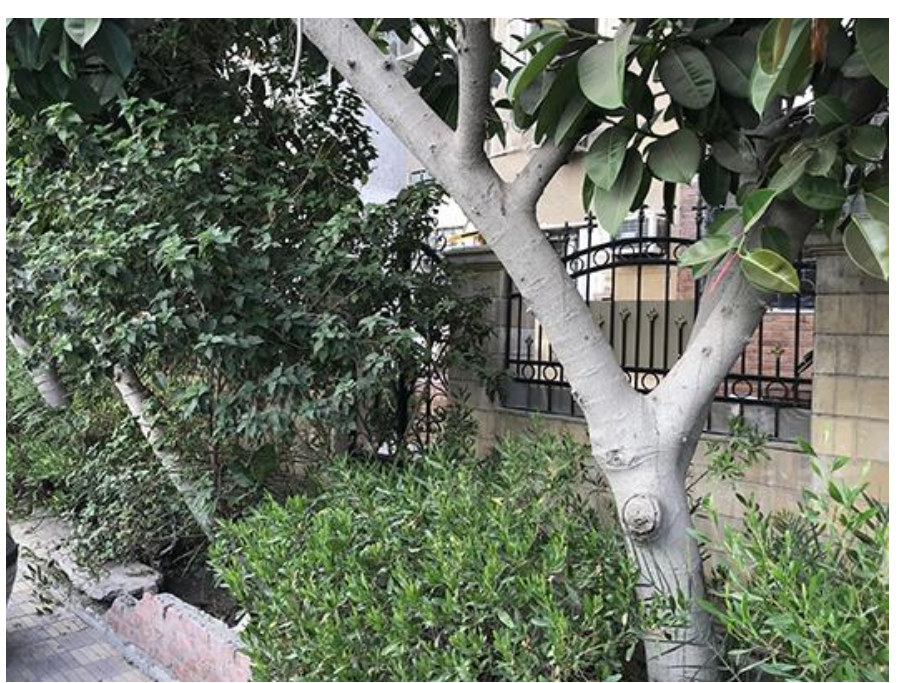

Figure 5. Creating Social Privacy, the author; 2019

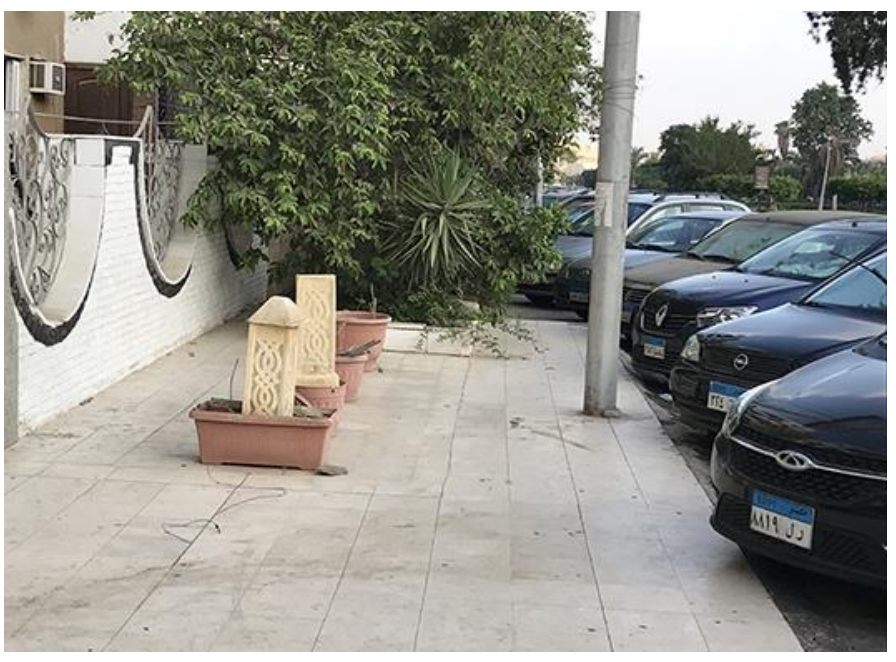

Figure 6. Informal Territorial Borderlines, the author; 2019

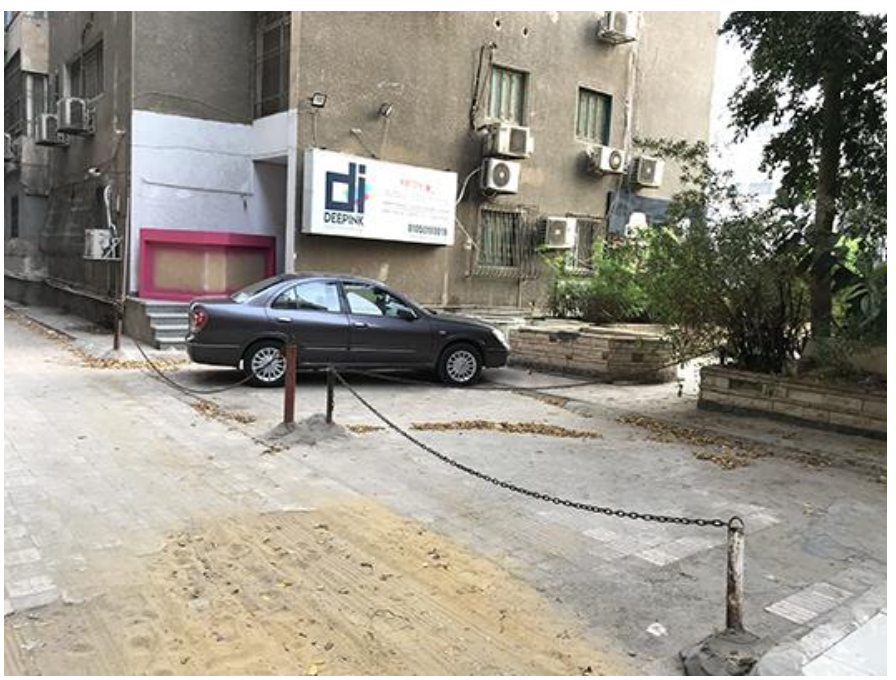

Figure 7. Reserving Spots for Private Parking, the author; 2019 


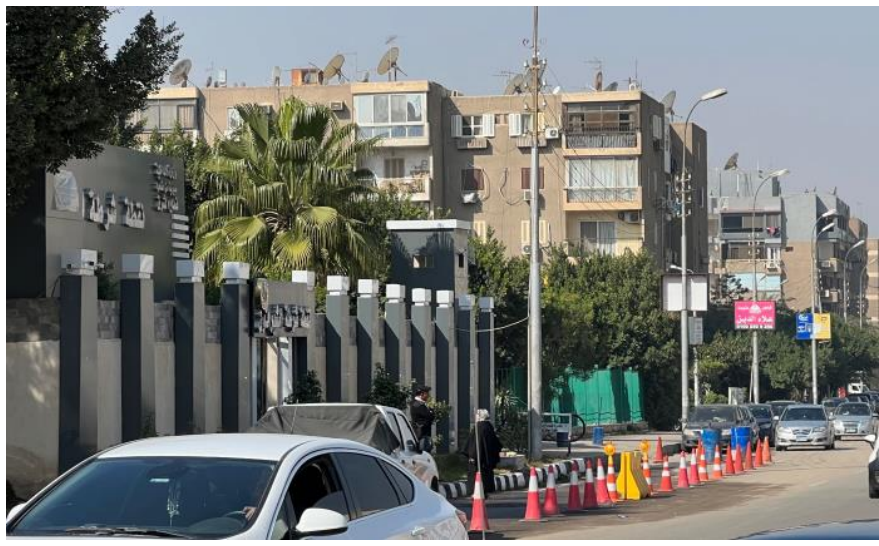

Figure 8. Occupying the Set-back and the Pavement with the Structure, Permanente Formal Territorial Borderlines; A Police Station, the author; 2021

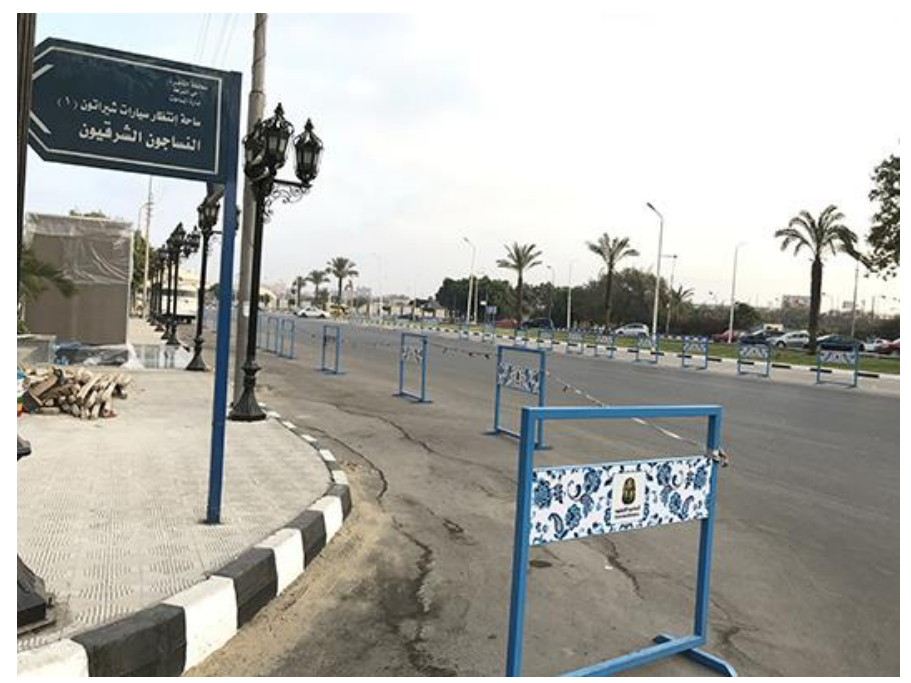

Figure 9. Reserving Parking Areas for a Private Company, before Working Hours (at 6 AM), the author; 2021

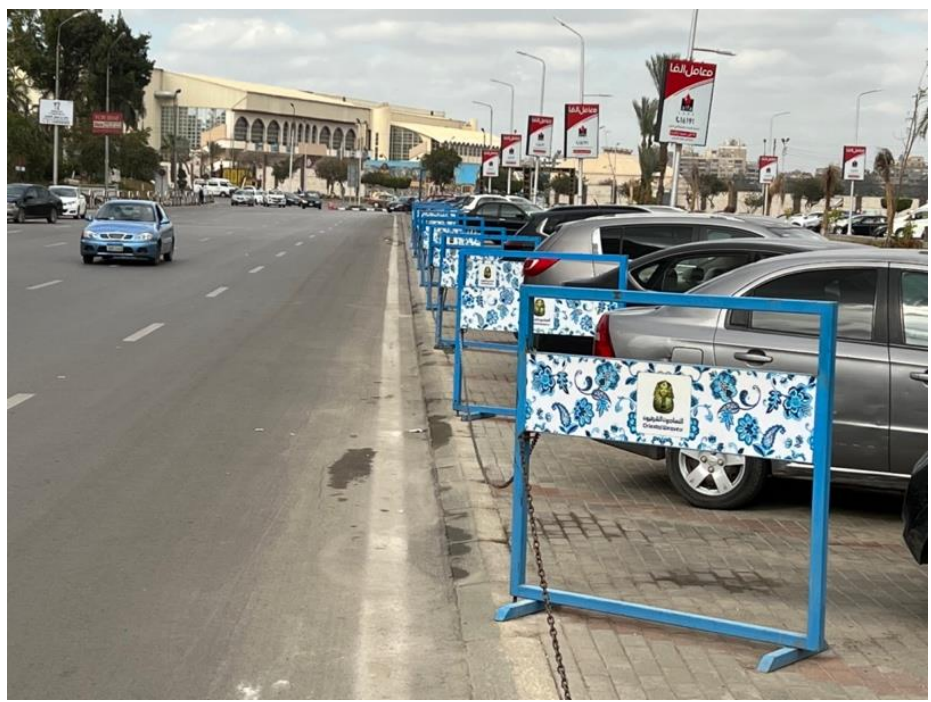

Figure 10. Reserving Parking Areas for a Private Company, during Working Hours (at 11 AM), the author; 2021 


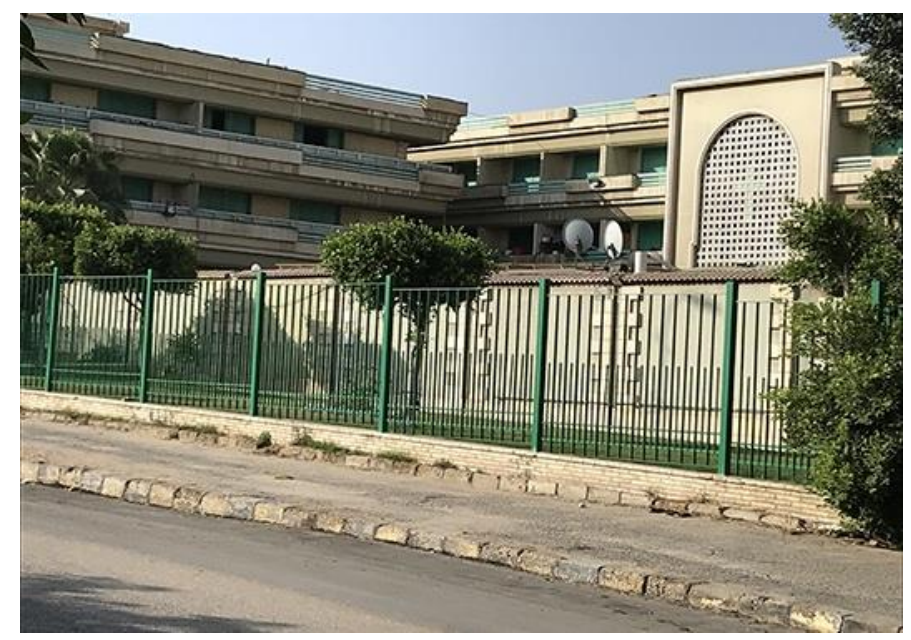

Figure 11. Influential Institution's Semi-permanent Territorial Borderlines, the author; 2019

However, the second sector of Sayyed Zakaria Street presents medium-density and high-income housing, no significant commercial activities were spotted, and its green island was never developed but became a vast vacant sandy area (Figure 12). Responding to authorities neglect, the residents took matters into their own hands and imprinted the place with various informal activities. Trees are used to block the lousy view, provide shade, express the self, and protect the family's social privacy (Figure 13). Bollards in various shapes were used as territorial borderlines for security and reserving parking spots (Figure 14 and Figure 15). Shrubs were planted in front of houses, and pavements were finished according to various tastes and financial means (Figure 6 and Figure 16). Human activities were rarely observed in the second sector except for domestic helpers washing cars in the early morning and a few people jogging or passing by.

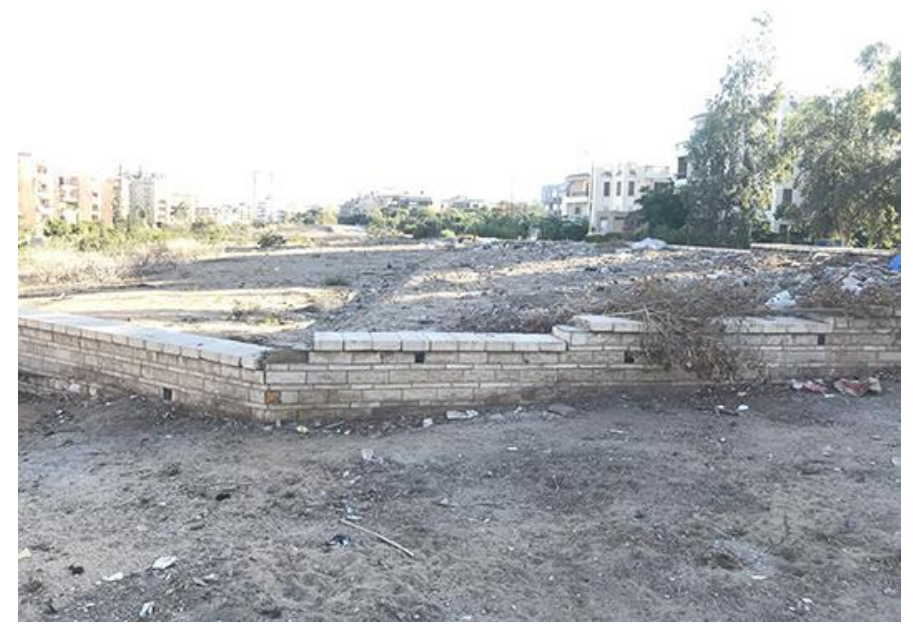

Figure 12. The Middle Island in Sayyed Zakaria Street Second Sector, the author; 2019 


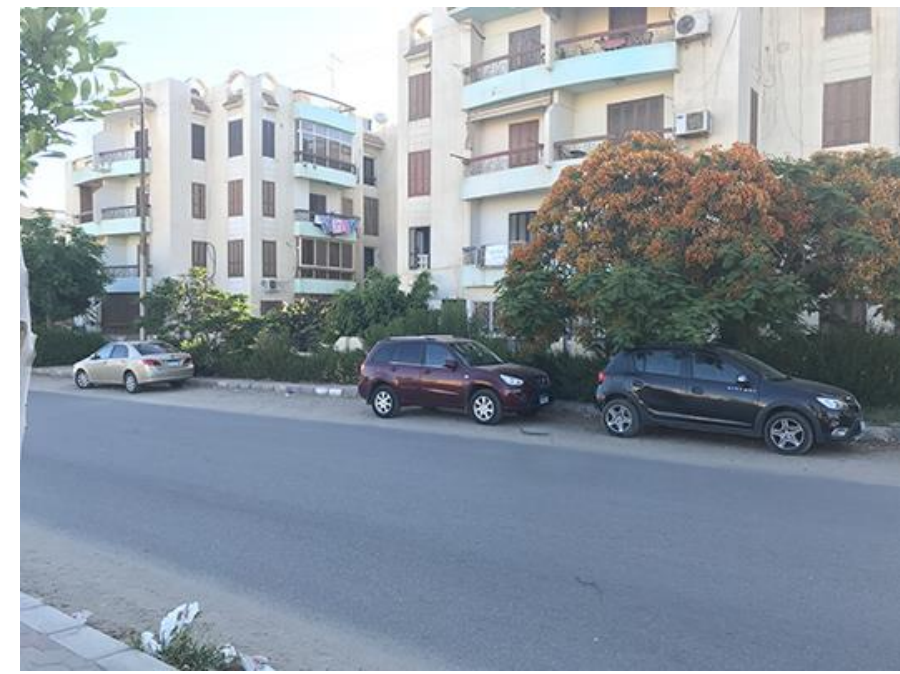

Figure 13. Providing Shade and Protecting Social Privacy, the author; 2019

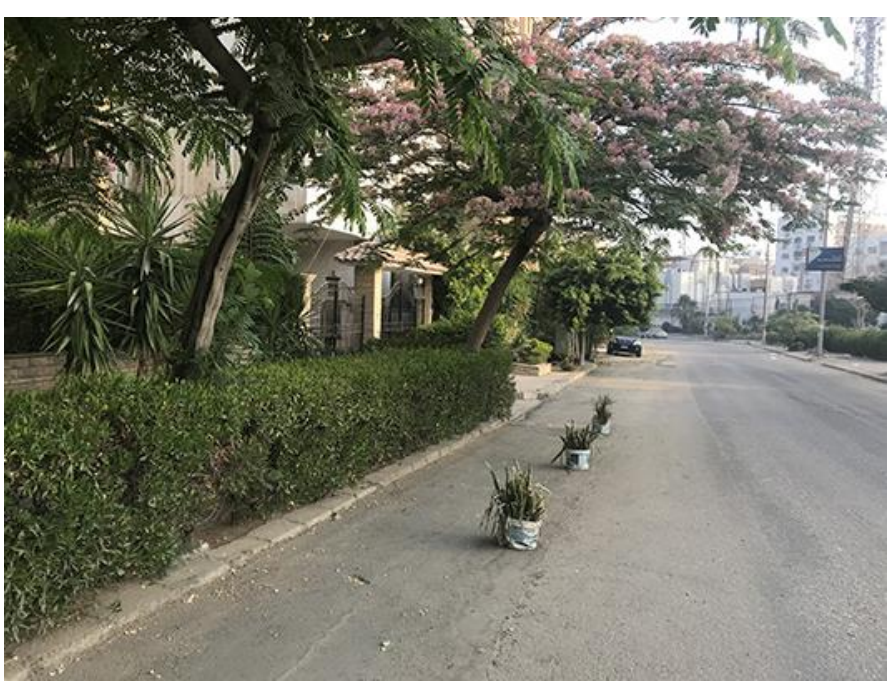

Figure 14. Pots as Bollards, the author; 2019

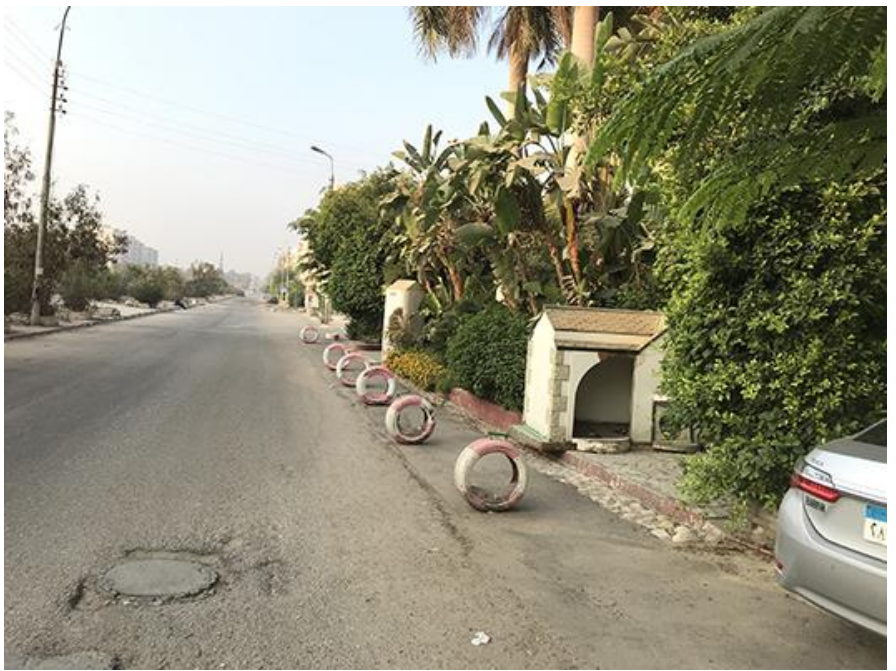

Figure 15. Car Tiers as Bollards, the author; 2019 


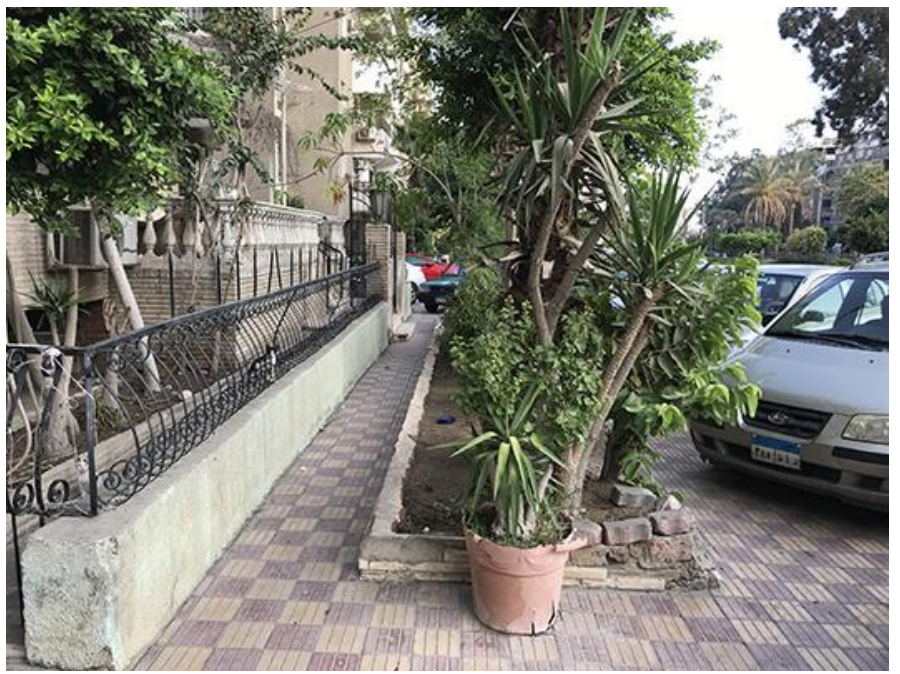

Figure 16. Pavement Finishing, the author; 2019

\subsection{Informal Placemaking in El-Arab Housing}

A significant street in El-Arab housing (henceforth; El-Arab) informal area is selected for comparison. El-Arab is an informal and low-income housing in western Heliopolis. The area presents high residential density, and the selected street is defined by buildings varying between ten to twelve floors. The street is approximately the third of Sayyed Zakaria Street width. Various commercial activities are found in the street, such as street vendors, coffee-houses, convenience stores, pharmacies, repair shops, and local fast-food restaurants. The street is neither equipped for cars nor paved for pedestrians, accommodating various human activities; eating, drinking, working in the open air, waiting, relaxing, socialising, and children playing. Few trees were planted in front of coffee-houses, workshops and mosques for shading. Graffiti is widely used for various purposes, such as memorising religious occasions or pilgrimage and cheering for a football team. The insufficient urban services and small apartments made people conceive the street extension of their private space.

\section{Informal Placemaking; Flexibility, Similarities, Diversities and Power}

Expressing individual actions in placemaking (informal placemaking) comes under pressure [25, p. 48]. Rejecting them lies in our 'synoptic viewing' of how the city must appear (see [26]), ranging from the old British planning school to the American vehicleoriented and Dubai models. Moreover, such rejection influences our understanding of placemaking and the community right to assert the place order. While formal urbanism is appreciated, Tonkiss argued that informal practice is considered inadequate urban production but can be overlooked if the elites suit them [27]. However, placemaking should not be based on the notion of legality and formality; it must consider how people live and use place rather than on the institutional definition of legality [28]. Evaluating a prosperous public place should be according to its potential in attracting people to perform many activities like sitting, eating, selling goods, and searching for comfortable experiences $[2$, pp. 687-688]. People are not creating places to break the law; they create them for needed activities and emotions. Placemaking reveals essential information about how people modify places according to their daily needs and actions [28].

The placemaking process should be evaluated according to its objectives, such as creating place identity, sense of place, and attachment. As a significant placemaking objective, place identity is achieved through self-descriptive items indicating the social groups people belong to or aspire to belong to and their territorial decisions [15, pp. 2387-2388]. 
Moreover, if placemaking objectives are met, and the collective memory of a place is expressed in the numerous layers that govern its order [29, p. 1034], the process should present valuable experiences. Individual interventions in Sheraton Residence and other areas should be valuable if they meet the placemaking objectives.

Investigating informal placemaking in Sheraton Residence and El-Arab presents evidence for residence modifying, adapting and contributing to the place identity in a cumulative form. It can be argued that both areas present various individual interventions; classy (which might be accepted) and marginalised (which is usually rejected). The preliminary observation created the impression of this argument since both areas demonstrate various urban qualities in imposing individual action on the public space. Individual actions in Sheraton Residence introduced places with high-quality pavements, trees, shrubs, bollards, flower boxes, grass, treatments items, luxury commercial activities, bank branches and services. On the other hand, ordinary shops, street vendors, public and private activities in front of coffee shops, workshops and graffiti dominated the individual intervention in el-Arab. While trees, for example, are excessively used in Sheraton Residence, shelters and human activities dominate the public space in el-Arab. Coffee shops and commercial activities were identified in both areas alike, but they presented various architectural qualities and activity styles. Branded international commercial activities were adapted in Sheraton Residence and local ones in el-Arab.

\subsection{Identity of Informal Placemaking}

Sheraton Residence and El-Arab presented places of individual and group interests; place identity was not created by the formal urban structure or the top-down decisionmaking process. In both areas, residents' engagements in placemaking came in an individual but cumulative actions. Despite the preliminary impression that individual interventions in both cases are not the same, they both created place identity and sense of place. The importance of place identity is unlimited to enhancing the sense of place, which is essential for health and wellbeing [30] and connecting the sense of place to place attachment [8, p. 2]. Aiming to attract human activities as placemaking should [31], reflecting the self [32], modifying and contributing to placemaking, the residents and users created places in both areas and imprinted them with identities. As Dane et al. [33] expected, a sense of place in Sheraton Residence and El-Arab reflects an overall experience developed over time. Since the sense of place defines all bonds between individuals and their places [8], [34] place attachment can be expected. Formal urbanism in Sheraton Residence failed to transform spaces into places and create a place identity. On the other hand, informal placemaking transformed formal spaces into places promoting various identities and senses.

\subsection{Flexibility and Informal Placemaking}

Flexibility is a significant placemaking objective. If urban planning is considered a process aiming at maximising the residents quality of life [35] and maintaining the feeling of home in place, it requires flexible solutions. Carmona and Sieh identified various dimensions for place flexibility, such as the ability of users to modify, adapt and contribute to placemaking [36]. However, the classic view in Egypt promotes formal and expert-led urbanism, which is far from being flexible. Cairo witnessed a long term urban deterioration in expert-led urbanism of the early and middle of the $20^{\text {th }}$ century, such as Shobra, elHelmeia el-Jedidah and Abdien, as the rich kept moving out to newly developed areas [37, p. 186], probably, for the lack of urban flexibility.

Individual solutions in Sheraton Residence and El-Arab were flexible in dealing with various conditions and users ever-changing needs. Soft-scape, pavements, non-permanent territorial borderlines, social and commercial activities, billboarding, and graffiti are flexible placemaking items. Such a flexible attitude strengthened the sense of place, as 
defined by Berg et al. [38]. On the other hand, formal urban interventions are far from being flexible.

\subsection{Similarities in Informal Placemaking}

Similarities in placemaking in various areas should enhance our understanding of their urban value. Informal placemaking in Sheraton Residence and El-Arab showed similarity on the conceptual level and diversity in application. Placemaking objectives in both areas were quite similar. Attracting human activities, promoting commercial uses and creating territorial identities reflect similarities on the conceptual level. It seems that territorial identity was practised on the conceptual level in both areas by various groups, including the authorities and influential institutions. Banini and Ilovan [39] pointed out that territorial identity is defined by tangible and intangible features that involve place attachment and belonging. The territorial identity harbours emotional and symbolic meanings attached to creating meaningful places. Interestingly, while ordinary individuals created non-permanent territorial borderlines, the authorities created permanent ones (see Figure 8).

\subsection{Diversities of Informal Placemaking in Cairo}

What created the preliminary impression of the diversity in placemaking between Sheraton Residence and El-Arab, was the place visual quality. Diversity is generated due to various socio-economic forces, personal tastes, and site conditions, resulting from applying various materials and luxury items. It can be identified in soft-scaping, pavement's finishing materials, coffee shops qualities and brands, and bollards types and forms. Diversity was found between Sheraton Residence and El-Arab and between various places in Sheraton Residence itself.

Despite that Sayyed Zakaria Street is considered one planning entity, its second sector showed evident diversity in the use of soft-scaping and bollards as territorial borderlines. Its large apartments and villas might have contributed to limiting the application of coffee shops. Interviewees presented arguments for using private clubs, malls, and homes for social gatherings and entertainment. The second sector showed limited commercial activities; a commercial greenhouse, a bank branch and a grocery store. The excessive use of trees, flower-boxes and shrubs can be related to residents lifestyles. Diversity in lifestyle contributed to the diversity of placemaking items and quality.

While informal placemaking in Sheraton Residence was identified on street sides and the middle island, it conquered the street in El-Arab; it is used for open-air work and activities, social gathering and as children playground. The street use as a motorised traffic element in Sheraton Residence seems to contribute to such activities displacement. In ElArab, the street as the public life core became part of the private realm. Bollards are used in Sheraton Residence to reserve parking spots for private use and are mainly used in ElArab for blocking activities in front of residential buildings', shops', and mosques' entrances. It can be argued that reserving parking spots for private use is similar to blocking the spot from activities, but their application showed an apparent diversity in types and forms (Figure 7, Figure 14 and Figure 15 ). Pavement finishing materials are presented in various qualities; low-cost tiles are used in El-Arab and luxury tiles in Sheraton Residence.

\subsection{Informal Placemaking and the Urban Power}

Power can be traced in Cairo, practised by individuals, influential groups and the authorities [14], and informal placemaking is among those traces. To adequately comprehend the informal placemaking in Sheraton Residence, we should consider its relationship to the silent protest as Bayat [40], [41] explained; informal placemaking is some form of resistance contributing to our comprehension of the city as a complex project. Informal placemaking in Sheraton Residence and El-Arab introduced self-expression, territoriality 
behaviour, rejecting certain formal urban aspects and tackling the authorities urban neglect and injustice. Residents and users in both areas practice their power in asserting their place order by making decisions and taking action. Place users ability to modify, contribute and create territorial identities reflects their power practice.

As an act of urban resistance occurs by everyday activities in the public place [42], resisting forms of urban neglect take several forms of 'silent actions' [25, p. 46] and place contestations. Residents and users challenged the authority power in placemaking by transforming formal spaces into places in Sheraton Residence and tackling the authorities urban neglect by creating places in El-Arab (as a neglected area). Influential groups and authority representations practice informality by creating permanent to semi-permanent territorial borderlines and blocking or limiting activities in certain spots. Soft-scaping, commercial functions and activities, pavement, graffiti, territoriality and shading elements are used to express the community's silent resistance to the authorities urban neglect. In both areas, people made decisions and took actions for claiming and controlling the place.

However, other forces influence users' actions, such as their financial means. The economy seems to be a joint governing force in informal placemaking in Sheraton Residence and $e l-A r a b$. Place users took matters into their hands by applying various materials according to their financial conditions and social status. Luxury landscaping is promoted in Sheraton Residence, and low-cost items were widely adapted in the el-Arab. Permanent territorial borderlines are challenged in El-Arab due to users financial status and vulnerable social conditions. Commercial activities and street vendors reflected the shopper's financial power and players ability to modify and adapt (Figure 17). Coffee shops are widely presented for social gatherings, entertainment and relaxation to compensate residents small apartments (Figure 18). Diversity in the visual appearance in Sheraton Residence and El-Arab seems more related to the economic forces and players' position in the power network than their contribution to placemaking.

Since informal placemaking is the people ability to modify, adapt and create place identity, sense of place and territoriality, Sheraton Residence presented a typical case of informal placemaking, challenging the argument of relating informality to low-income and -educated groups. Informal placemaking in Sheraton Residence and El-Arab is created as a bottom-up process. Place identity is reflected through direct and indirect users' involvement in transforming the space into a place and claiming it their own.

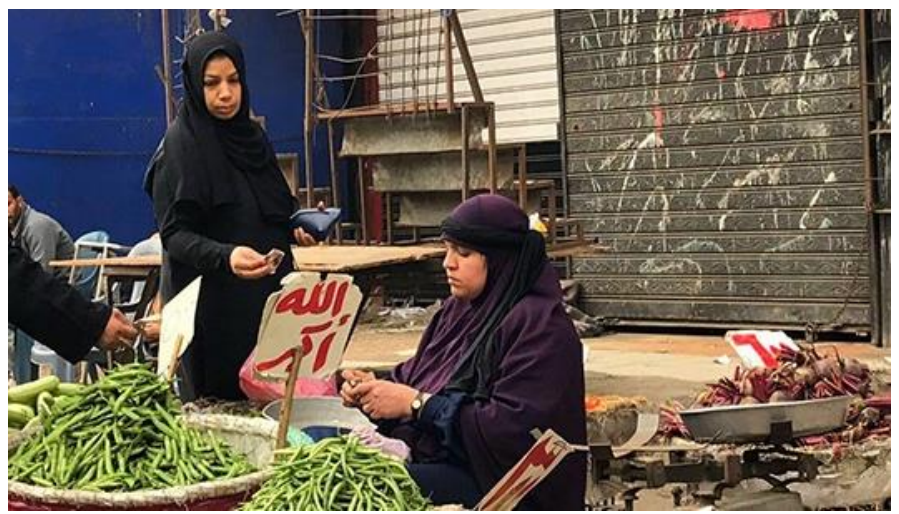

Figure 17. Street Vendors in El-Arab Housing, the author; 2010 


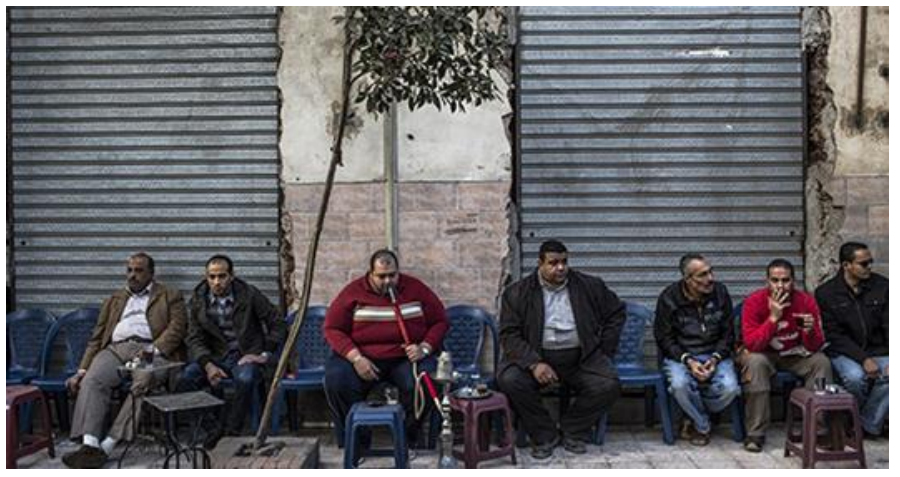

Figure 18. Entertainment and Social Gathering by a Coffee Shop in El-Arab Housing, the author; 2010

\section{Conclusions}

The general impression that only the poor and low-educated classes practise informal placemaking is incorrect. Informal placemaking is practised by various classes and by the authorities as well. The idea that informal placemaking belongs to the poor and unintellectual must be argued and classifying places as informal and illegal needs to be revised. The author suggests re-thinking informal placemaking as meaningful activities rather than a category system.

Informal placemaking in Sheraton Residence and El-Arab showed similarities on the conceptual level by introducing actions, self-expression and practising residents right to assert the order of their places. Diversity is produced in relationship to personal taste and financial means.

The residents engaged in placemaking to satisfy their need for urban identity, place belonging and sense of place.

Individuals and cumulative decisions and actions create informal placemaking in Sheraton Residence. It is created due to residents attitudes for modifying, adapting and engagement in placemaking.

Urban players practised power in territorial identities, which are used as signs and symbols for their ability in making decisions. Informal placemaking can be interpreted as the reflections of place contestations and community protests against urban neglect.

Whether the informal placemaking is promoted to tackle the authorities urban neglect, create privacy, territorial identities, or self-expression, the outcome can be seen as an urban silent protest.

\section{References}

[1] D. Sims, Understanding Cairo: The Logic of a City out of Control. Cairo: The AUC Press, 2011.

[2] M. Jamhawi, R. Alshawabkeh, and E. Alobaidat, 'Spatial Modelling of Transformation of Public Open Spaces in Zarqa, Jordan', Int. J. Sustain. Dev. Plan., vol. 15, pp. 685-703, Aug. 2020, DOI: 10.18280/ijsdp.150511.

[3] E. Toolis, 'Restoring the Balance between People, Places, and Profits: A Psychosocial Analysis of Uneven Community Development and the Case for Placemaking Processes', Sustainability, vol. 13, p. 7256, Jun. 2021, DOI: 10.3390/su13137256.

[4] B. Gatersleben, K. Wyles, A. Myers, and B. Opitz, 'Why are places so special? Uncovering how our brain reacts to meaningful places', Landsc. Urban Planning, vol. 197, pp. 1-7, Feb. 2020, doi: DOI: 10.1016/j.landurbplan.2020.103758.

[5] Economist Intelligence Unit, 'The Global Liveability Index 2019', The Economist, Oct. 22, 2019. https://www.eiu.com/n/theglobal-liveability-index-2019/ (accessed Jun. 17, 2021).

[6] Mercer, 'Quality of Living City Ranking', 2019. https://mobilityexchange.mercer.com/insights/quality-of-living-rankings (accessed Jun. 17, 2021).

[7] Monocle, 'Quality of Life Survey - Issue 125 - Magazine', Monocle, Made with love by DADI+ (https://dadi.tech/) in London, England, 2020. Accessed: Jun. 17, 2021. [Online]. Available: https://monocle.com/magazine/issues/125/quality-of-life-survey/

[8] F. Christy, G. Raissa, S. Sihotang, and K. Wijaya, 'Critical Analysis of Urban Livability Measures Based on the Perspective of Placemaking', IOP Conf. Ser. Earth Environ. Sci., vol. 764, p. 012016, May 2021, DOI: 10.1088/1755-1315/764/1/012016. 
[9] R. Hambleton, 'Enhancing the power of place', Eurocities, Mar. 25, 2021. https://eurocities.eu/latest/enhancing-the-power-ofplace/ (accessed Jul. 28, 2021).

[10] R. Koch and A. Latham, 'Inhabiting Cities, Domesticating Public Space: Observing Change in the Public Life of Contemporary London', 2021, pp. 374-383. DOI: 10.4324/9781351202558-56.

[11] H. Lefebvre, 'Le droit a la ville.', in Kofman, E and Lebas, E (Eds.) Writings on Cities, Oxford: Blackwell Publishing, 1968.

[12] R. Koch and A. Latham, 'Inhabiting Cities, Domesticating Public Space: Observing Change in the Public Life of Contemporary London', 2021, pp. 374-383. DOI: 10.4324/9781351202558-56.

[13] I. Wight, 'An Integral Perspective on Place, Placemaking and Placemakers [Integral Placemaking as Wellbeing by Design: A Poiesis of Sophrosynes?]'. Sep. 25, 2020.

[14] S. Saad, 'Urban Injustice, Socio-economic Neglect and Segregation in Cairo', Int. Res. J. Eng. Technol. IRJET, vol. 7, no. 8, pp. 2796-2804, Aug. 2020.

[15] S. Clayton et al., 'Cross-Cultural Validation of A Revised Environmental Identity Scale', Sustainability, vol. 13(4), pp. 2387-2399, Feb. 2021, DOI: 10.3390/su13042387.

[16] A. Wyckoff, 'Definition of Placemaking: Four Different Types",' Plan. Zoning News, 2014, Accessed: Dec. 17, 2016. [Online]. Available: available at: http://www.canr.msu.edu/uploads/375/65814/4typesplacemaking_pzn_wyckoff_january2014.pdf

[17] G. Ashworth, 'The Instruments of Place Branding: How is it Done?', Eur. Spat. Res. Policy, vol. 16, pp. 9-22, 2009.

[18] G. Pflieger and C. Rozenblat, 'Introduction. Urban Networks and Network Theory: The City as the Connector of Multiple Networks', Urban Stud., vol. 47, no. 13, pp. 2723-2735, Jan. 2010, DOI: 10.1177/0042098010377368.

[19] S. Saad, 'Cairo in The Age of Great Urban Transformations. Changes in Street Patterns Only, or a Shift in Power Networks as Well?', in The Future and the Built Environment, Istanbul, Aug. 2019, pp. 389-408.

[20] S. Saad, 'Whose Place is this? Places, Publicness and Authoritarian Power in Cairo during Jan. 25 Revolution', Int. Res. J. Eng. Technol., vol. 8, no. 11, pp. 1025-1031, Nov. 2021.

[21] M. Ríos-Rodríguez, C. Rosales, M. Lorenzo, G. Muinos, and B. Hernández, 'Influence of Perceived Environmental Quality on the Perceived Restorativeness of Public Spaces', Front. Psychol., vol. 12, p. 644763, Apr. 2021, DOI: 10.3389/fpsyg.2021.644763.

[22] A. M. Topaloğlu, 'Placemaking in Everyday Life', in Topaloğlu, A. M. (2020). Nia, H. A. (Ed.), New Approaches in Contemporary Architecture and Urbanism, Istanbul: Cinius Yayınları Publications, 2020, pp. 136-144. [Online]. Available: https://doi.org/10.38027/N142020ICCAUA316250

[23] S. Saad, 'Acts of Creating Meaningless Similarities. Top-down Placeless-making in Heliopolis, Cairo', J. Public Space, forthcoming.

[24] M. Cervera Alonso de Medina, M. Gascon, and S. Bell, 'A Transdisciplinary Approach to Recovering Natural and Cultural Landscape and Place Identification: A Case Study of Can Moritz Spring (Rubí, Spain)', Int. J. Environ. Res. Public. Health, vol. 18, Feb. 2021, DOI: 10.3390/ijerph18041709.

[25] S. Knierbein and J. Hou, 'Public Space, Civic Dignity, and Urban Resistance in the Age of Shrinking Democracy, Trans. Assoc. Eur. Sch. Plan., pp. 46-58, 2020, DOI: 10.24306/TrAESOP.2020.01.005.

[26] R. Coleman, “The Synoptic City: State, "Place" and Power', Space Cult., vol. 22, no. 1, pp. 1-15, 2018.

[27] F. Tonkiss, Cities by Design: The Social Life of Urban Form. Cambridge, UK: Polity Press, 2013.

[28] E. Ravazzoli and S. Toso, 'Spatial Relations of Informal Practices in Cairo Streetscape', in Urban [in] formality: tensions, conflicts and breakups in the struggle to belong, Berlin, 2013, vol. 09, pp. 1-21.

[29] R. Kumar, 'Overview: Social Spaces in Urban Areas', Int. J. Eng. Technol., vol. 4, no. 4, pp. 1032-1039, Apr. 2017.

[30] A. Lovell, R. Gray, and E. Boucher, 'Place, health and community attachment: Is community capacity associated with self-rated health at the individual level?', SSM Popul. Health, vol. 3, pp. 153-161, Dec. 2017, DOI: https://doi.org/10.1016/j.ssmph. 2016.12.002.

[31] N. Ujang, 'Place Attachment and Continuity of Urban Place Identity', Procedia - Soc. Behav. Sci., vol. 49, pp. 156-167, Jan. 2012, DOI: 10.1016/j.sbspro.2012.07.014.

[32] M. Nielsen-Pincus, T. Hall, J. E. Force, and J. D. Wulfhorst, 'Sociodemographic effects on place bonding', J. Environ. Psychol., vol. 30, no. 4, pp. 443-454, Dec. 2010, DOI: 10.1016/j.jenvp.2010.01.007.

[33] G. Dane, A. Borgers, and T. Feng, 'Subjective immediate experience during large-scale cultural events in cities: A geotagging experiment', Sustainability, vol. 11, no. 20, pp. 1-19, 2019, DOI: https://doi.org/10.3390/su11205698.

[34] M. Lewicka, 'Place attachment: How far have we come in the last 40 years?', J. Environ. Psychol., vol. 31, no. 3, pp. 207-230, 2011, DOI: https://doi.org/10.1016/j.jenvp.2010.10.001.

[35] A. Kaminsky, 'What is Urban Planning?', wiseGEEK, 2020. http://www.wisegeek.com/what-is-urban-planning.htm (accessed Nov. 20, 2020).

[36] M. Carmona and L. Sieh, Measuring Quality in Planning. Managing the Performance Process. London: Routledge, 2004.

[37] G. Selim, 'Between Order and Modernity Resurgence Planning in Revolutionary Egypt', J. Urban Hist., vol. 42, no. 1, pp. 180200, Jan. 2016, DOI: 10.1177/0096144214566980.

[38] P. Berg, H. Larose, S. Magnussen, and T. Arentz, 'Sense of place, shopping area evaluation, and shopping behaviour', Geogr. Res., pp. 1-15, Jun. 2021, DOI: 10.1111/1745-5871.12485.

[39] T. Banini and O. Ilovan, 'Introduction: dealing with territorial/place identity representations', in In: Banini T., Ilovan O.-R. (eds.), Representing Place and Territorial Identities in Europe, vol. 127, Springer, 2021, pp. 1-19. 
[40] A. Bayat, 'Politics in the City-inside-out', City Soc., vol. 24, no. 2, pp. 110-28, 2012.

[41] A. Bayat, Life as Politics: How ordinary people change the Middle East. Stamford: Stanford University Press, 2010.

[42] M. Castells, The Power of Identity. The Information Age: Economy, Society and Culture, vol. 2. West Sussex, UK: Wiley-Blackwell, 2010. 